\title{
점소성-손상모델 기반 피로균열 진전속도 전산 평가법 개발
}

\author{
김 슬 기 ${ }^{1} \cdot$ 김 정 현 $^{1} \cdot$ 이 치 승 ${ }^{1} \cdot$ 김 명 현 $^{1} \cdot$ 이 제 명 ${ }^{1+}$ \\ ${ }^{1}$ 부산대학교 조선해양공학과
}

\section{Development of Computational Evaluation Method for Fatigue Crack Growth Rate based on Viscoplastic-Damage Model}

\author{
Seul-Kee Kim ${ }^{1}$, Jeong-Hyeon Kim ${ }^{1}$, Chi-Seung Lee ${ }^{1}$, Myung-Hyun Kim ${ }^{1}$ and Jae-Myung Lee ${ }^{1+}$ \\ ${ }^{1}$ Departement of Naval Architecture and Ocean Engineering, Pusan National Univ., Busan, 609-735, Korea
}

\begin{abstract}
In this paper, computational evaluation method for fatigue crack growth rate(FCGR) based on material viscoplastic-damage model is proposed. Viscoplastic-damage model expressing material constitutive behavior of $7 \%$ nickel steel is introduced and is implemented into commercial finite element analysis(FEA) code, ABAQUS, as a user defined material subroutine(UMAT) for application in the FEA environments. Verification of developed UMAT and material parameters of material model are carried out by uniaxial tensile test simulations of $7 \%$ nickel steel. Moreover, jump-in-cycles procedure and rearrangement of critical damage are employed and also implemented to the ABAQUS UMAT for fatigue damage analysis. Typical FCGR test results such as relationship between crack length and number of cycles and relationship between $d a / d N$ and $\Delta K$ could be obtained from FCGR test simulation using developed UMAT and these results are compared with experimental results in order to verify of proposed computational method.
\end{abstract}

Keywords : fatigue crack growth rate(FCGR), damage mechanics, finite element analysis, ABAQUS user defined material subroutine (UMAT)

\section{1. 서 론}

선박 및 해양플랜트를 포함하는 산업구조물은 주기적인 하 중에 노출되어 있으며, 이를 통한 구조물의 균열전파 및 구 조파손은 심각한 문제를 야기하므로 피로해석 또는 피로 수 명 평가의 필요성은 널리 인식되어 왔다. 피로균열 진전속도 (FCGR)는 균열을 가지는 부재의 반복응력 하 균열성장 특 성을 정의하는 파괴역학 파라미터로 응력확대계수 진폭과 $1 \mathrm{cycle}$ 당 균열성장량의 관계식인 Paris' law로 표현되며, 이의 적분을 통해 균열을 내포하는 구조부재 또는 산업구조 물의 피로수명을 계산할 수 있어 실제 산업현장에서도 활용 도가 높다(Anderson, 2005).

피로균열 진전속도 시험은 주로 실험적 방법을 통해 수행 되고 있으며(Chung and Kang, 1989; Kwon and Yang,

\footnotetext{
${ }^{\dagger}$ Corresponding author:

Tel: +82-51-510-2342; E-mail: jaemlee@pusan.ac.kr Received June 26 2014; Revised September 22014

Accepted October 222014

(C) 2015 by Computational Structural Engineering Institute of Korea
}

2002), 이는 가장 정확하고 신뢰성 높은 방법이라 볼 수 있 으나, 가혹한 하중환경의 구축 및 시험수행을 위한 물리적 시간, 비용 등은 실험적 방법을 통한 피로균열 진전속도 평 가에 걸림돌로 작용하고 있다. 따라서 상기 제약요건들에 따 른 보완 또는 대체적 방법으로 전산해석을 활용한 피로균열 진전속도 평가의 시도가 지속적으로 이루어져 왔다.

전산해석을 활용한 피로균열 진전속도 평가는 cohesive zone model $(\mathrm{CZM})$ 을 통해 주로 이루어지고 있으며, 재료 또는 구조부재의 피로균열 진전을 효과적으로 모사하고 있다. $\mathrm{CZM}$ 이론은 균열 진전해석에서 가장 광범위하게 사용되는 기 법으로 균열선단에 cohesive zone을 두고 cohesive tractionseparation 관계를 정의하여 이들을 기준으로 균열의 진전 을 판단한다. de-Andres 등은 3 차원 cohesive 요소 및 비 가역 cohesive law를 통해 알루미늄 shaft의 피로균열 현상

\footnotetext{
This is an Open-Access article distributed under the terms of the Creative Commons Attribution Non-Commercial License(http://creativecommons. org/licenses/by-nc/3.0) which permits unrestricted non-commercial use, distribution, and reproduction in any medium, provided the original work is properly cited.
} 
분석과 피로수명 평가를 수행하였으며(de-Andres et al. 1999), Yang 등은 준(quasi)취성 재료의 균열 생성 및 발전 을 전산모사하기 위해 CZM을 활용하는 시뮬레이션 방법을 제시하였다(Yang et al., 2001). 또한 Roe와 Siegmund는 Paris' law가 아닌 실제 재료의 separation 과정을 반영한 interface를 따라 성장하는 피로균열에 대하여 연구하였다 (Roe and Siegmund, 2003). 이러한 CZM을 활용한 피로 균열 진전모사는 시편의 형상 특성과 파괴 특성 값이 주어진 상태로 지배방정식(governing equation)을 풀기 때문에 해 석을 위해서 초기 균열의 위치와 형태가 정의되어야만 하며 이러한 파괴 특성 값은 실험에 의해 획득하여야만 하는 한계 성을 가지고 있다고 볼 수 있다.

본 연구에서는 재료 점소성-손상모델(viscoplastic-damage model)을 기반으로 한 피로균열 진전속도 전산평가를 수행 하였다. 재료 균열발생 및 진전을 표현, 예측하는 역학모델로 재료 내부에 분포하는 미세결함을 손상(damage)이라는 상 태변수로 정의하고 이의 축적을 모사하는 손상모델을 활용하 였으며(Lemaitre and Desmorat, 2005), 이들 재료 구성 모델은 상용 유한요소해석 프로그램인 ABAQUS에서 제공하는 사용자 정의 서브루틴(user defined subroutine, UMAT)에 탑재되었다. 개발 서브루틴을 이용한 FCGR 전산평가 결과 는 실험결과와의 비교를 통해 제안 전산 평가방법의 유효성 을 검증하였다.

\section{2. 제안 FCGR 전산 평가법}

\section{1 구조 손상해석 적용 및 Jump-in-cycles 과정}

일반적으로 손상의 발생 및 진전을 구조해석에 접목시키는 방법의 선택은 파손관련 문제의 해결에 있어서 주요한 고려 사항으로 인식되고 있으며, 대표적으로 두 가지의 방법이 손 상의 구조해석 적용을 위한 전산해석 기법으로 알려져 있다.

첫 번째 전산해석 방법은 Fig. 1과 같이 응력장(stress field)과 같은 구조해석의 결과를 토대로 손상발전방정식을 계산하여 구조의 손상 정도를 평가하고 수명을 예측하는 방 법으로 전산해석 과정 동안 변형률 및 응력의 계산에 있어서 손상의 정도와는 무관하게 계산되기 때문에 uncoupled method로 불리고 있다. 두 번째 방법은 이와는 반대로 Fig. 2 와 같이 전산해석 과정 동안 변형률 및 응력, 그리고 손상이 상 호 연관성을 가지며 계산을 수행하는 방법으로 fully coupled method로 불리며 uncoupled method에 비해 높은 정확성 을 보인다고 알려져 있다(Benallal et al., 1991).

본 연구에서는 계산결과의 정확성 및 해석시간의 적절성을

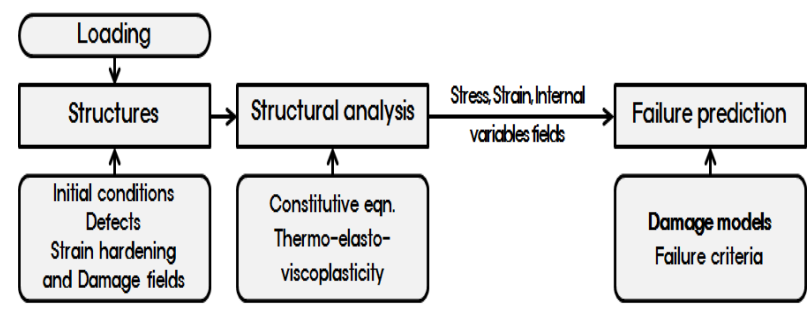

Fig. 1 Uncoupled method for structural damage analysis

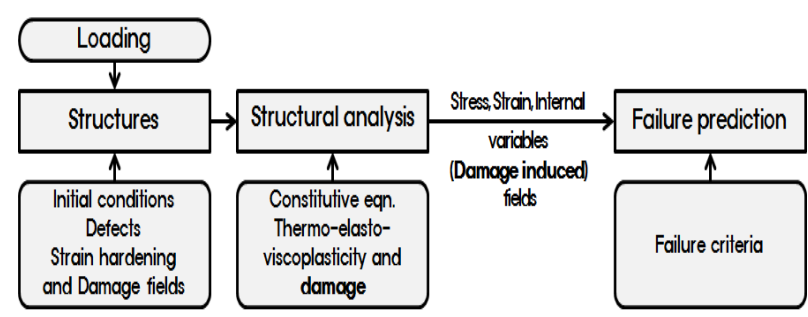

Fig. 2 Fully coupled method for structural damage analysis

위하여 위 두 방법을 결합한 형태를 사용하였다. FCGR 테스 트 시뮬레이션 대부분의 시간동안은 재료 점소성-손상모델을 기반으로 시편의 손상을 계산하는 fully coupled method로 수행되며 jump-in-cycles 과정은 uncoupled method 방법 으로서 손상 계산에 적용되었다. Jump-in-cycles 과정은 피 로손상 문제에서 손상축적이 안정한(stable) 구간의 손상 축 적 값을 선형으로 계산하고 그 일정 주기(cycle)가 jump하는 방법이며 다음과 같이 jump 주기가 계산된다(Lemaitre and Desmorat, 2005).

$$
\overline{\Delta N}=\frac{\overline{\Delta \omega}}{\left.\frac{\delta \omega}{\delta N}\right|_{N_{s}}}
$$

여기서, $\overline{\Delta N}$ 은 jump 하는 주기 구간(blocks of number of cycles)이며, $\overline{\Delta \omega}$ 는 jump 주기 구간에서의 손상 축적양 이다. 그리고 $\left.\frac{\delta \omega}{\delta N}\right|_{N_{s}}$ 는 손상축적이 안정한(stable) 구간에서 의 한 주기 당 손상축적 양이다. $\overline{\Delta \omega}$ 는 임계손상 (critical damage, $\omega_{c r}$ )값의 $1 / 50$ 정도를 사용하도록 권장하고 있으 며(Lemaitre and Desmorat, 2005), jump 구간을 지난 손상량은 다음과 같이 계산된다.

$$
\omega\left(N_{s}+\overline{\Delta N}\right)=\omega\left(N_{s}\right)+\left.\frac{\delta \omega}{\delta N}\right|_{N_{s}} \overline{\Delta N}
$$

여기서, $N_{s}$ 는 손상축적이 안정한 구간에서의 주기(cycle) 이다.

FCGR 테스트 시뮬레이션을 위한 본 연구의 구조 손상해석 


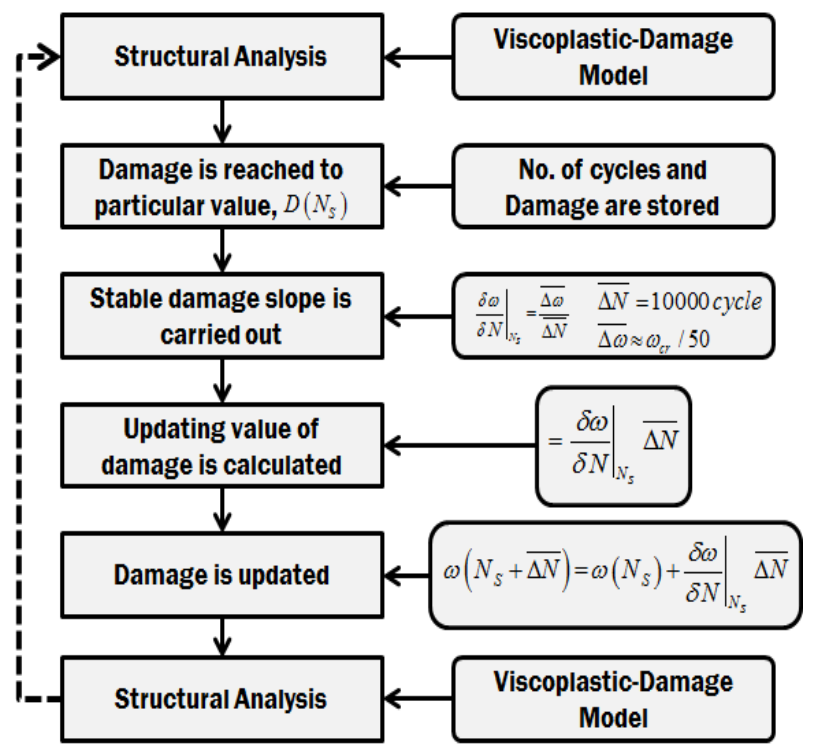

Fig. 3 Algorithm for damage calculation including jump-in-cycles procedures

계산 알고리듬은 Fig. 3과 같다. 본 연구에서는 $\left.\frac{\delta \omega}{\delta N}\right|_{N_{s}}$ 를 수 치적으로 도출하기 어렵다고 판단하여 알고리듬과 같이 $\overline{\Delta \omega}$ 가 $\omega_{c r}$ 의 $1 / 50$ 이하의 값을 가지는 $\omega_{N_{s}}$ 와 $\overline{\Delta N}$ 를 임의로 정 하여 jump-in-cycles 과정이 계산되도록 하였다. 계산에 사용된 $\left.\omega\right|_{N_{s}}, \overline{\Delta N}$ 은 각각 $1.0 \mathrm{E}-10,1,000 \mathrm{cycles}$ 이다. 해석 시 사용된 점소성-손상모델은 각각 Bodner-Partom 점소성 모델, Bodner-Chan 손상모델이며(Bodner, 2002), 해당 모델 및 jump-in-cycles 과정은 상용 유한요소해석 코드인 $\mathrm{ABAQUS}$ 에서 제공하는 사용자정의 재료 서브루틴(user defined material subroutine, UMAT)에 탑재되었다.

\section{2 점소성-손상모델}

일반적으로 변형률속도는 탄성지배 변형률속도와 소성지배 변형률속도로 분리 가능하며 그 변형률분리식은 다음과 같다.

$$
\dot{\varepsilon_{i j}}=\dot{\varepsilon}_{i j}^{e}+\dot{\varepsilon}_{i j}^{i e}
$$

여기서, $\varepsilon_{i j}^{e}$ 는 탄성변형률속도, $\varepsilon_{i j}^{i e}$ 는 비탄성변형률속도이 다. 탄성변형률속도는 일반적인 Hooke 법칙의 시간미분 항 에서 주어진다.

$$
\begin{aligned}
& \dot{\sigma_{i j}^{e}}=D_{i j k l} \dot{\varepsilon}_{k l}^{e} \\
& D_{i j k l}=2 G\left[\frac{1}{2}\left(\delta_{i k} \delta_{j l}+\delta_{i l} \delta_{j k}\right)+\frac{\nu}{1-2 \nu} \delta_{i j} \delta_{k l}\right]
\end{aligned}
$$

여기서, $G$ 는 전탄 탄성계수, $\delta_{i j}$ 는 Kronecker함수이다. 비탄성 변형률 항은 Prandtl-Reuss 법칙을 따르며, 다음과 같이 표현된다.

$$
\begin{aligned}
\dot{\varepsilon_{i j}^{i e}} & =\lambda s_{i j} \\
s_{i j} & =\sigma_{i j}-\frac{1}{3} \sigma_{k k} \delta_{i j}
\end{aligned}
$$

여기서, 스칼라 $\lambda$ 는 소성승수(plastic multiplier)이며 다 음의 Bodner-Partom형태의 점소성모델로 표현된다(Bodner, 2002)

$$
\lambda=\sqrt{\frac{D_{0}^{2}}{J_{2}} \exp \left[-\left(\frac{Z^{2}}{3 J_{2}}\right)^{N}\right]}
$$

여기서, $D_{0}$ 와 $N$ 은 재료정수, $J_{2}$ 는 편차응력의 2 차 불변 량, $Z$ 는 내부변수로 본 연구에서는 등방경화만을 고려하며 다음과 같이 주어진다(Bodner, 2002).

$$
Z=Z_{1}+\left(Z_{0}-Z_{1}\right) \exp \left(-m W_{P}\right)
$$

여기서, $Z_{0}, Z_{1}$ 은 등방경화 내부변수로서 각각 항복, 포화 응력을 나타낸다. $m$ 은 등방경화율을 조절하는 함수이며. $W_{P}$ 는 축적 소성일을 의미한다.

한편, 재료의 성능저하를 기술하기 위한 손상발전 방정식 은 다음과 같다(Bodner and Chan, 1986).

$$
\begin{aligned}
& \dot{\omega}=\frac{P}{H}\left[\ln \left(\frac{1}{\omega}\right)\right]^{\frac{P+1}{P}} \omega \dot{Q} \\
& \dot{Q}=\left[\alpha \sigma_{\max }^{+}+\beta \sqrt{3 J_{2}}+\gamma I_{1}^{+}\right]^{r} \\
& \lambda=\sqrt{\frac{D_{0}^{2}}{J_{2}} \exp \left[-\left(\frac{Z^{2}(1-\omega)^{2}}{3 J_{2}}\right)^{N}\right]}
\end{aligned}
$$

여기서, $\omega$ 는 내부 손상을 정량적으로 나타내는 손상변수, $P, H, r$ 은 재료정수, $\sigma_{\max }^{+}$는 최대 인장 주응력, $I_{1}^{+}$는 응력의 1 차 불변량을 나타낸다. 한편, $\alpha+\beta+\gamma=1$ 을 만족하는데, 실험적 연구에 의해 일반적인 금속재료는 $\beta=0.75, \gamma=$ 0.25로 알려져 있다(Hayhurst and Leckie, 1977). 식 (12)는 손상 변수가 적용된 Bodner-Partom 형태 점소성모 델의 소성승수이다.

\section{$2.3 \mathrm{ABAQUS}$ 사용자정의 서브루틴 개발}


본 연구에서는 점소성-손상모델의 $\mathrm{ABAQUS} \mathrm{UMAT}$ 적용 을 위한 implicit 기반 유한요소 정식화과정을 수행한다. $\mathrm{UMAT}$ 은 사용자가 요소의 각 적분점마다 재료 거동을 정의 할 수 있게 하며, 사용자는 응력 텐서와 해 의존 상태변수 (Solution Dependent Variable, SDV), 재료 자코비언 행렬을 각 증분마다 업데이트하여야 한다. 이상 변형률 증분 과 시도응력(trial stress)은 다음과 같다.

$$
\begin{aligned}
& \Delta \varepsilon=\varepsilon_{n+1}-\varepsilon_{n} \\
& \sigma_{n+1}^{\text {trial }}=\sigma_{n}+D: \Delta \varepsilon
\end{aligned}
$$

응력은 다음과 같이 갱신된다.

$$
\sigma_{n+1}=\sigma_{n+1}^{\text {trial }}-\Delta \lambda D: s_{n+1}
$$

$\Delta \lambda$ 는 $\Delta \lambda=\lambda \Delta t$ 이므로 다음과 같이 표현된다.

$$
\Delta \lambda=\Delta t \sqrt{\frac{D_{0}^{2}}{J_{2}} \exp \left[-\left(\frac{Z^{2}(1-\omega)^{2}}{3 J_{2}}\right)^{N}\right]}
$$

또한, 각 증분마다 갱신되어야 하는 변수들(SDV)은 다음 과 같이 나타낼 수 있다.

$$
\begin{aligned}
& \Delta Z=m_{1} \Delta \lambda\left[Z_{1}-Z\right] 2 J_{2} \\
& Z_{n+1}=Z_{n}+\Delta Z \\
& \omega_{n+1}=\omega_{n}+\frac{P}{H}\left[\ln \left(\frac{1}{\omega}\right)\right]^{\frac{P+1}{P}} \omega_{n} \dot{Q} \Delta t
\end{aligned}
$$

Implicit 기반 유한요소 정식화과정 중 재료 자코비언 행 렬은 저자의 이전 연구(Lee et al., 2013)에서 ATS (Algorithmic Tangential Stiffness) 텐서로 유도되었으며 본 연구에서 이를 UMAT에 탑재하여 활용하였다.

균열의 전파를 모사하는 방법에는 여러 가지가 존재하나, 본 논문에서는 요소약화법(element weakening method) 을 적용하였다(Mishnaevsky, 2007). 또한, 파단기준으로 는 임계손상에 도달한 요소를 약화시킴으로써 균열을 모사하 는, 손상역학에서 가장 널리 사용되는 임계손상법(critical damage method)을 사용하였다.

본 논문 제안 전산 FCGR 평가 알고리즘을 Fig. 4에 보 인다. 전산 FCGR 평가는 (1) 재료 인장(압축) 테스트, (2) 재료거동 모사 재료 구성 모델의 개발, (3) 개발 재료 모델 의 유한요소해석 적용(재료 서브루틴 개발) 및 재료 테스트

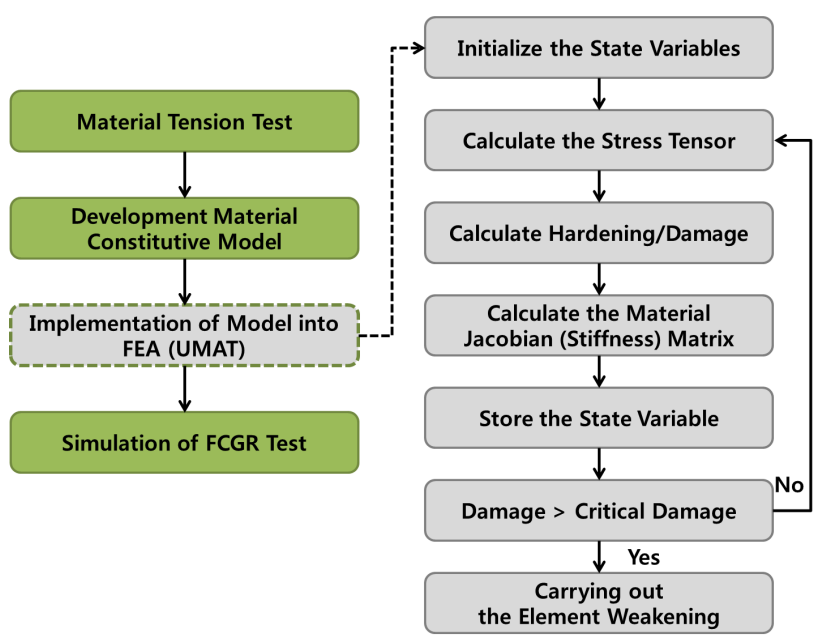

Fig. 4 Procedure of computational FCGR test(left) and numerical algorithm of UMAT calculation(right)

시뮬레이션을 통한 검증, (4) FCGR 테스트 시뮬레이션의 과정으로 수행하게 된다. ABAQUS UMAT 계산 알고리즘 역시 Fig. 4에 함께 나타나 있으며, 사용한 재료 모델을 바 탕으로 계산한 결과(응력, 변형률, 손상 등)를 가지고 각 요 소의 손상정도 또는 파단 여부를 판단하게 된다. 이는 $\mathrm{FCGR}$ 전산 평가 과정에 있어 재료거동(응력-변형률 관계)을 충분 히 모사할 수 있는 재료모델의 사용 또는 개발의 중요성을 나타낸다.

\section{3. 수치시뮬레이션 예제}

\section{1 재료인장 시험 시뮬레이션}

전술한 개발 $\mathrm{ABAQUS} \mathrm{UMAT}$ 의 검증을 위하여 상온 재 료인장 시험 시뮬레이션을 수행하였다. 재료인장 시험 시뮬 레이션은 전술한 jump-in-cycles 과정은 고려하지 않았으며 대상 재료는 $7 \%$ 니켈강이다. Fig. 5는 재료인장 시험 시뮬 레이션을 위한 유한요소모델을 나타내며, rod-type 시편의 유한요소모델은 3 차원 감차적분 요소로 구성되었으며, 요소 수는 15,840 개, 절점 수는 20,648 개 이다. 유한요소모델의 하중/경계조건은 시편의 아래쪽은 $x, y, z$ 각 방향으로 병 진, 회전 구속하였으며, 시편의 위쪽은 $y$ 방향으로 $1.0 \mathrm{E}-4 / \mathrm{s}$ 의 변형률 속도로 변위 제어하였다. Fig. 6 은 재료 인장 시 험 시뮬레이션 결과를 나타내며, 본 논문에서 채택한 재료 점소성-손상 모델 기반 $\mathrm{ABAQUS} \mathrm{UMAT}$ 의 유효성을 확인 할 수 있다. 이상 재료인장 시험 시뮬레이션의 결과로 얻은 $7 \%$ 니켈강 재료정수를 Table 1에 정리한다. 얻은 재료정 수는 전산 FCGR 테스트 해석 시 재료정수로 사용한다. 


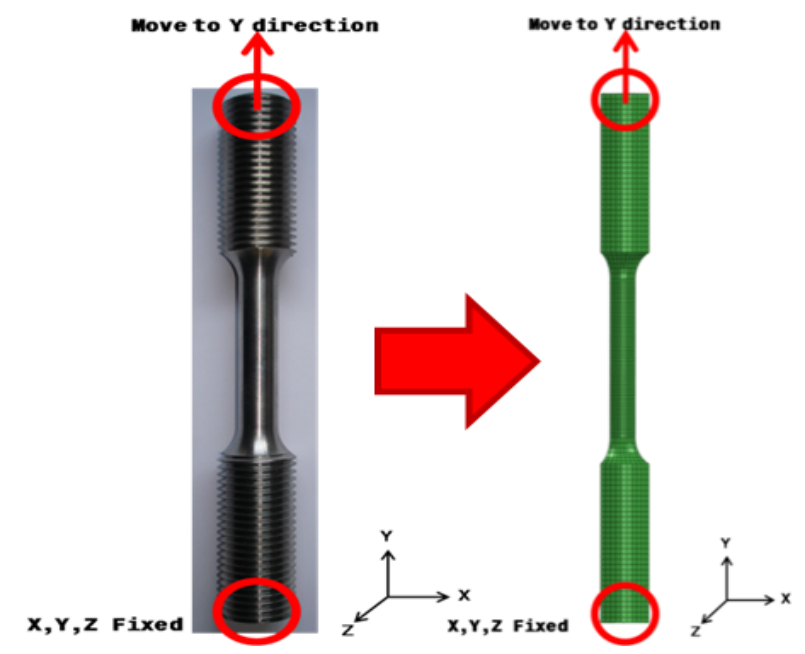

Fig. 5 Finite element model for simulation of uniaxial tensile tests

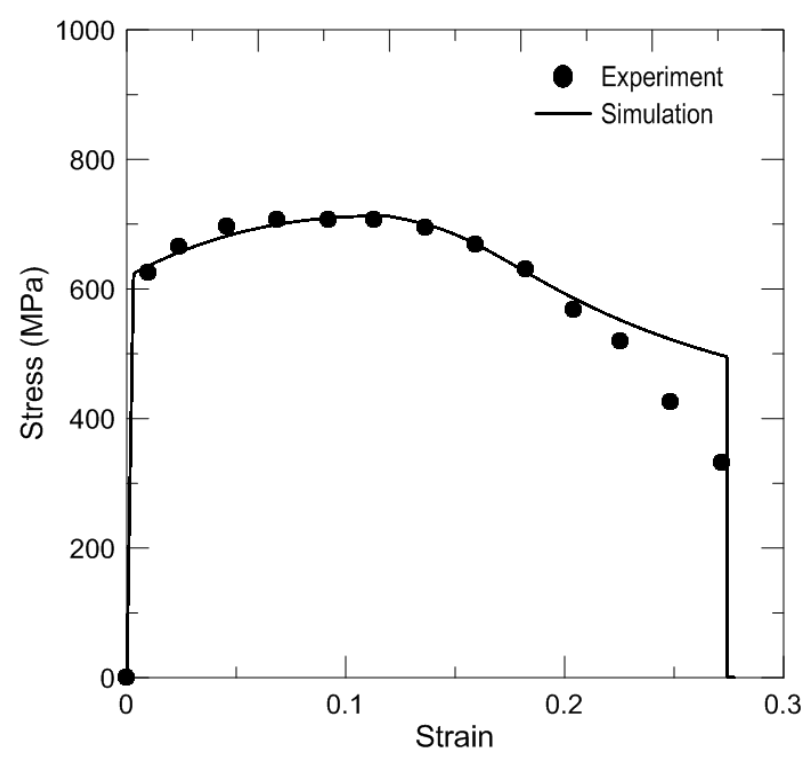

Fig. 6 Comparison of uniaxial tensile tests of $7 \%$ nickel steel with experimental result at room temperature

Table 1 Material parameters of damage coupled constitutive model for computational FCGR test

\begin{tabular}{|c|c|c|c|c|c|}
\hline$E(\mathrm{GPA})$ & $\nu$ & $Z_{0}(\mathrm{MPa})$ & $Z_{1}(\mathrm{MPa})$ & $D_{0}\left(\mathrm{~s}^{-}\right)$ & $m$ \\
\hline 181.1 & 0.33 & 1450 & 1380 & 1.0 & 0.025 \\
\hline$n$ & $b$ & $h$ & $r$ & $\omega_{c r}$ & \\
\hline 2.05 & 4.28 & $7.25 \mathrm{E}+18$ & 5.5 & 0.2 & \\
\hline
\end{tabular}

\section{2 임계손상 조정 및 피로 예비균열 시뮬레이션}

일반적으로 피로하중 하 손상축적 계산에 있어 two-scale damage model을 채택하여 피로 손상해석을 수행한다 (Lemaitre, 1990; 1992). 이는 피로파괴에 있어 손상의 발생 및 축적이 미시규모(micro scale)의 소성 변형에 기인

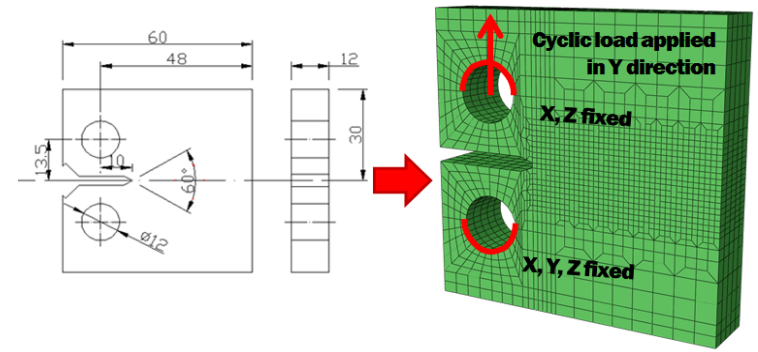

Fig. 7 Finite element model of compact tension(CT) specimen for ABAQUS

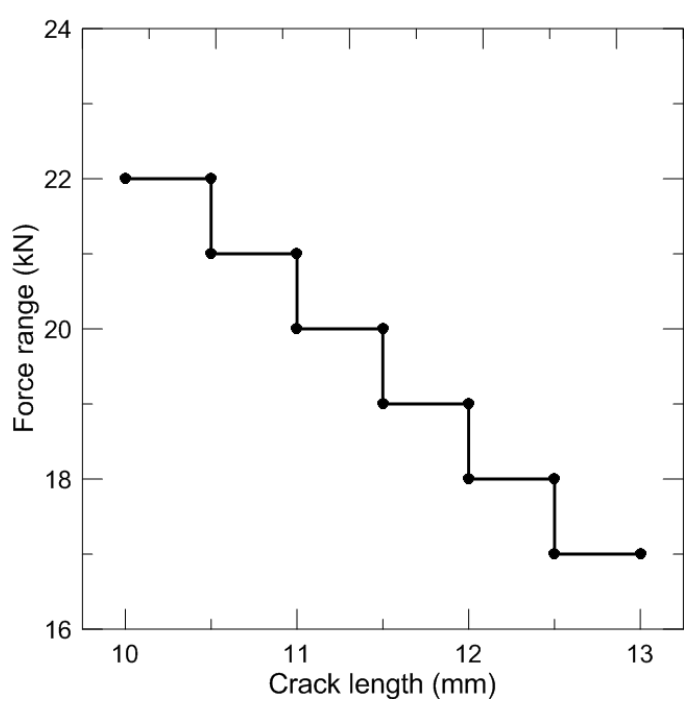

Fig. 8 Actual K-decreasing by stepped force shedding

한다는 현상을 바탕으로 하며, two-scale damage model은 거시-미시규모(macro or meso scale-micro scale)에서의 축적 등가 소성변형률(accumulated equivalent plastic strain)과 같은 재료 내부 상태변수 관계의 정의가 필요하다. 이러한 재료 내부 상태변수의 거시-미시규모 관계 정의는 실 험에 의한 결과를 통해 이루어지며, 손상 관련 내부 상태변 수의 경우, 그 측정이 쉽지 않다고 알려져 있다(Lemaitre, $1990 ; 1992)$. 따라서 본 논문에서는 피로하중 하 손상축적 계산 및 균열진전 시뮬레이션을 위해 임계손상 값의 조정을 통해 피로 손상해석을 수행하였다. 임계손상 값의 조정은 앞선 재료 인장시험에서 얻은 임계손상 값의 $1,1 / 100,1 / 10000$ 을 가지도록 하였으며, 각각의 경우에 대해 피로 예비균열 시뮬레이션을 실시하여 상온 실험결과와 비교하였다. Fig. 7 은 피로 예비균열 시뮬레이션 및 전산 FCGR 테스트를 위한 시편의 유한요소모델을 나타낸다(ASTM E647-13a, 2013). Compact tension(CT) 타입으로 3차원 8절점 가차적분 요 소가 사용되었으며 총 요소 수, 절점 수는 각각 6285 개, 8052 개 이다. 최소 요소 size는 crack tip 주위의 $1 \mathrm{~mm}$ 이 며, crack tip radius 역시 $1 \mathrm{~mm}$ 이다. 피로 하중조건은 


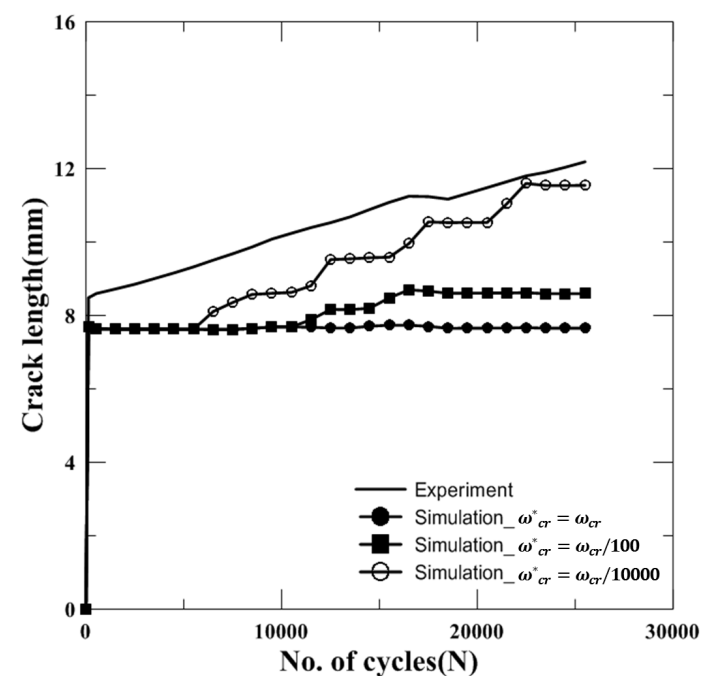

Fig. 9 Comparison of crack length and number of cycles relationships obtained from experimental fatigue precrack test and simulation according to varied critical damage

K-decreasing 과정에 따른 Fig. 8에 보이는 하중이력을 유 한요소모델의 jig hole 부분에 $\mathrm{MPC}$ 를 이용하여 설정하였으며 하중 frequency는 $10 \mathrm{~Hz}$ 이다(ASTM E647-13a, 2013). 하부 jig hole은 $x, y, z$ 방향으로 구속되며 상부 jig hole에 $y$ 방향으로 피로하중이 부여된다. 시뮬레이션 결과인 균열 길 이는 컴플라이언스법을 활용하여 측정하였다(ASTM E64713a, 2013).

Fig. 9은 실험, 시뮬레이션을 통한 피로 예비균열 테스트 결과로 균열길이와 주기 수(number of cycles) 관계를 나타 낸다. 피로 예비균열 시뮬레이션에서 전술한 jump-in-cycles 과정은 고려하지 않았으며, 임계손상 값을 $1 / 10000$ 로 조정 한 경우에 실험결과를 가장 잘 모사함을 확인하였다. 따라서 FCGR 테스트 본 시뮬레이션에서는 조정 임계손상 값의 $1 / 10000$ 값을 이용하였으며, 피로 예비균열 시뮬레이션 종료 시점의 각 요소들의 손상 축적 값을 본 시뮬레이션 초기 조 건으로 각 해당 요소에 부여하였다.

\subsection{FCGR 테스트 시뮬레이션}

이상 전술한 재료 점소성-손상 모델 탑재 $\mathrm{ABAQUS}$ UMAT을 기반으로 상온 FCGR 테스트 시뮬레이션을 수행 하였다. Jump-in-cycles 과정 역시 UMAT에 탑재되었으며, 재료 모델의 재료 정수는 앞선 재료 인장시험에서 획득한 재 료 정수를 바탕으로 임계손상 값만 조정 임계손상 값으로 수 정하였다. 시험편 유한요소모델 및 경계조건은 피로 예비균 열 시뮬레이션과 동일하나, 하중조건은 Fig. 7 시편의 상부 jig hole에 주기 당 최대, 최소하중이 각각 $18,0 \mathrm{kN}$, 하중
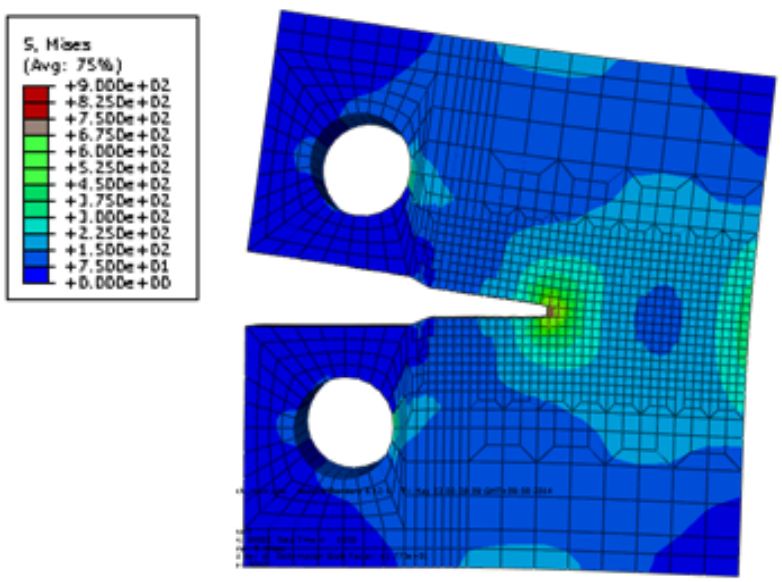

Fig. 10 Effective stress(von Mises) contour at a $=24 \mathrm{~mm}$

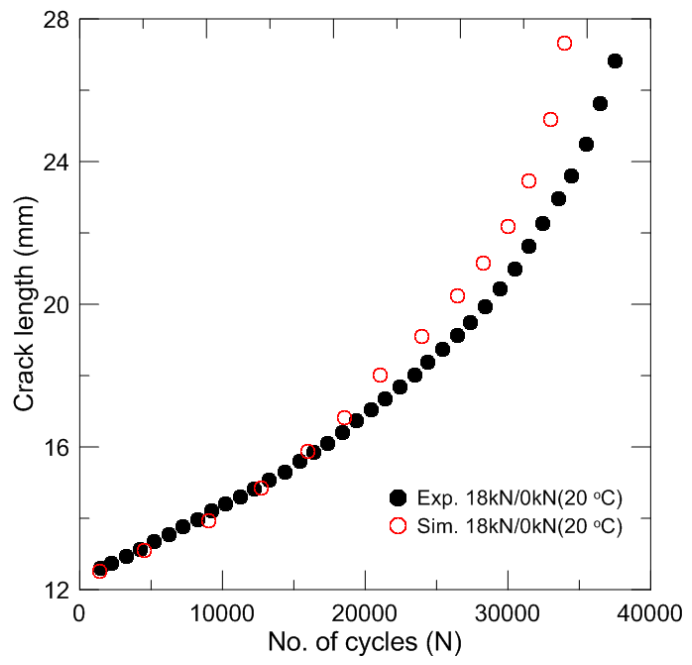

Fig. 11 Comparison of crack length and number of cycles relationship between experimental and computational evaluation

frequency가 $10 \mathrm{~Hz}$ 인 피로하중이 부여된다. Fig. 10은 FCGR 테스트 시뮬레이션 결과로 균열길이 $24 \mathrm{~mm}$ 에서의 시편 유효 응력 contour를 나타낸다. 또한 균열길이 $(a)$ 와 주기 수 (number of cycles)의 관계 및 1 cycle당 균열성장량 $(\mathrm{da} /$ $d N)$ 과 응력확대계수 진폭 $(\Delta K)$ 의 관계를 각각 Fig. 11과 Fig. 12에 나타내었다. 실험과 시뮬레이션으로 얻은 Paris' law 상수 $C$ 와 $m$ 은 Table 2 에 정리하였다.

한편, 본 전산 FCGR 테스트 시뮬레이션에서 jump-incycles 과정은 총 17 회 수행되었으며, 이로 인해 절약된 계산 cycle수는 $17,000 \mathrm{cycles}$ 이다. 점소성-손상모델 기반 fully coupled 해석은 1 cycle 계산에 4increments가 소요되며, 따라서 본 시뮬레이션에서 절약된 계산 increment는 68,000 increments이다. 제안 전산 FCGR 평가법이 계산 시간의 절약과 함께 실험결과를 일정 부분 모사함으로서 이의 유효 성을 확인할 수 있다. 


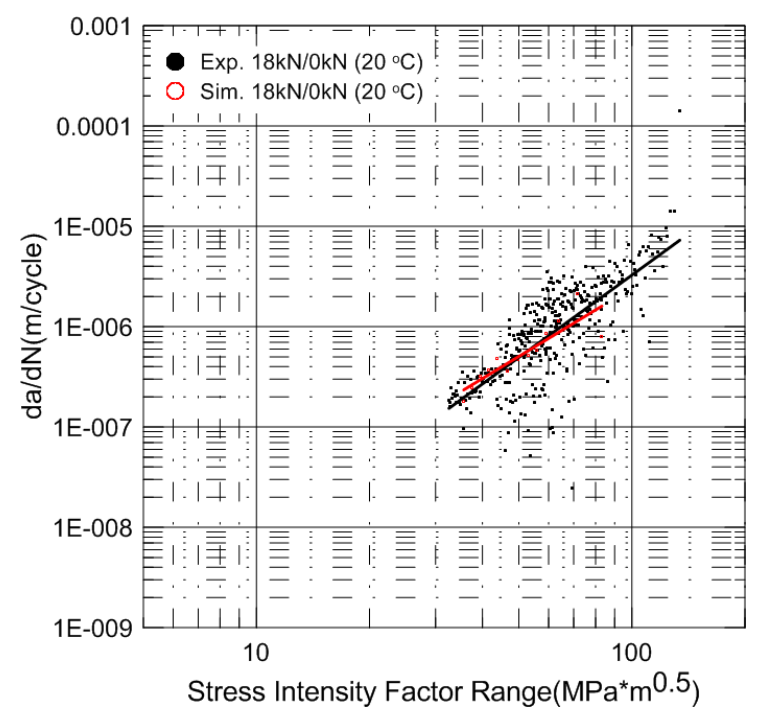

Fig. 12 Comparison of $d a / d N$ and stress intensity factor range relationship(Log-Log scale) between experimental and computational evaluation

Table 2 Paris' law constants obtained from experimental and simulation results

\begin{tabular}{|c|c|c|c|c|}
\hline Specimen type & Temperature & Method & $C$ & $m$ \\
\hline \multirow{2}{*}{$\begin{array}{c}\text { Compact } \\
\text { Tension }\end{array}$} & \multirow{2}{*}{$20{ }^{\circ} \mathrm{C}$} & Experiment & $2.17 \mathrm{E}-11$ & 2.57 \\
\cline { 3 - 5 } & & Simulation & $7.05 \mathrm{E}-11$ & 2.27 \\
\hline
\end{tabular}

\section{4. 결 론}

본 연구에서는 재료 점소성-손상모델을 기반으로 한 피로 균열 진전속도의 전산 평가를 수행하였다. $7 \%$ 니켈강 재료 거동 모사 점소성-손상모델은 상용유한요소해석 프로그램인 $\mathrm{ABAQUS}$ 에서 제공하는 사용자 정의 재료 서브루틴 UMAT 에 탑재되었으며 상온 재료 인장시험 시뮬레이션을 통해 재 료정수를 도출하였다. 또한 피로하중에 따른 손상 축적 계산 에 있어 임계 손상 값의 조정을 수행하였으며, 계산시간의 절감을 위해 jump-in-cycles 과정을 UMAT에 탑재하였다. 개발 UMAT을 통한 7\% 니켈강의 FCGR 테스트의 시뮬레 이션을 수행하였으며, 이를 실험결과와 비교하여 개발 UMAT 의 유효성을 검증하였다.

본 연구 결과를 아래와 같이 요약한다.

1) 전산 FCGR 평가를 위한 (1) 재료시험, (2) 재료거동 모사 구성 모델의 개발, (3) 개발재료 모델의 유한요소 해석 적용 및 검증 (4) 전산 FCGR 테스트의 과정을 가지는 프로시져를 제시하였다.

2) 피로손상 해석과정에 있어 계산시간 절감을 위해 jumpin-cycles 과정을 활용하였으며 이를 개발 UMAT에 탑 재하였다. 또한, 임계손상 값의 조정을 통해 피로 손상 축적 계산을 수행하였으며, 실험결과를 모사할 수 있는
조정 비율을 제시하였다.

3) 재료 점소성-손상 모델 및 jump-in-cycles 과정, 조정 임계손상 값이 적용된 $\mathrm{ABAQUS} U \mathrm{UMAT}$ 을 통해 7\% 니켈강의 FCGR 평가를 전산적으로 수행하였으며, 통 상의 실험결과에서 획득할 수 있는 균열길이 $(a)$ 와 주기 수(number of cycles) 관계 및 1cycle 당 균열성장량 $(d a / d N)$ 과 응력확대계수 진폭 $(\Delta K)$ 의 관계, Paris' law 상수인 $C$ 와 $m$ 을 시뮬레이션을 통해 획득하였다. 이들 결과는 실험 결과와 비교하여 제안 기법의 유효성 을 검증하였다.

본 연구의 결과는 상용유한요소해석 프로그램에서 제공하 는 사용자 정의 서브루틴을 기반으로 하고 있으며, 전산 FCGR 평가뿐만 아니라 피로하중 하 구조물의 균열진전 시 뮬레이션에도 적용 가능하리라 판단된다.

\section{감사의 글}

이 논문은 2013년도 정부(미래창조과학부)의 재원으로 한 국연구재단의 지원을 받아 수행된 연구임(No. 2011-00300 13). 이 논문은 2013년도 정부(교육부)의 재원으로 한국연 구재단의 기초연구사업 지원을 받아 수행된것 임 $(\mathrm{NRF}-2013$ R1A1A2A 10011206).

\section{References}

Anderson, T.L. (2005) Fracture Mechanics, 3rd ed., Taylor \& Francis, New York.

ASTM E647-13a (2013) Standard Test Method for Measurement of Fatigue Crack Growth Rates, Annual Book of ASTM Standards, vol. 3.01, ASTM International.

Benallal, A., Billardon, R., Lemaitre, J. (1991) Continuum Damage Mechanics and Local Approach to Fracture : Numerical Procedures, Comput. Methods Appl. Mech. \& Eng., 92, pp.141 155.

Bodner, S.R., Chan, K.S. (1986) Modeling of Continuum Damage for Application in ElasticViscoplastic Constitutive Equations, Eng. Fract. Mech., 25, pp.705 712.

Bodner, S.R. (2002) Unified Plasticity for Engineering Applications, 1st ed., Kluwer Academic \& Plenum Publishers, New York.

de-Andres, A., Perez, J.L., Ortiz, M. (1999) Elastoplastic Finite Element Analysis of Threedimensional Fatigue Crack Growth in Aluminum 
Shafts Subjected to Axial Loading, Int. J. Solids \& Struct., 36, pp.2231 2258.

Hayhurst D.R., Leckie F.A. (1977) Constitutive Equations for Creep Rupture, Acta Mater., 25, pp. 1059 1070.

Kwon, J.W., Yang, H.T. (2002) Fatigue Crack Growth Rates and Directions in STS304 under Mode I and Mixed Mode, Trans. Korean Soc. Mach. Tool Eng., 11(3), pp.102 109.

Lee, C.S., Yoo, B.M., Kim, M.H., Lee, J.M. (2013) Viscoplastic Damage Model for Austenitic Stainless Steel and Its Application to the Crack Propagation Ploblem at Cryogenic Temperatures. Int. J. Damage Mech. 22, pp.95 115.

Lemaitre, J., Chaboche, J.L. (1990) Mechanics of Solid Materials, 1st ed., Cambridge University Press.

Lemaitre, J. (1992) A Course on Damage Mechanics, 2nd ed. Springer.

Lemaitre, J., Desmorat, R. (2005) Engineering
Damage Mechanics, 1st ed., Springer.

Moes, N., Dolbow, J., Belytschko, T. (1999) A Finite Element Method for Crack Growth without Remeshing, Int. J. Numer. Methods Eng., 46, pp. $131 \sim 150$.

Mishnaevsky, L.Jr. (2007) Computational Mesomechanics of Composites, 1st ed., John Wiley \& Sons, New York.

Roe, K.L., Siegmund, T. (2003) An Irreversible Cohesive Zone Model for Interface Fatigue Crack Growth Simulation, Eng. Fract. Mech., 70, pp.209 $\sim 232$.

Stolarska, M., Chopp, D.L., Moes, N., Belytschko, T. (2001) Modelling Crack Growth by Level Sets in the Extended Finite Element Method, Int. J. Numer. Methods. Eng., 51, pp.943 960.

Yang, B., Mall, S., Ravi-Chandar, K. (2001) A Cohesive Zone Model for Fatigue Crack Growth in Quasibrittle Materials, Int. J. Solids \& Struct., 38, pp.3927 3944 .

본 논문에서는 재료 점소성-손상모델을 기반으로 한 피로균열 진전속도(FCGR) 전산 평가법을 제안한다. $7 \%$ 니켈강 재료 거동을 모사하는 점소성-손상모델을 소개하고, 이의 유한요소해석 플랫폼에의 적용을 위해 상용 유한요소해석 프로그램인 $\mathrm{ABAQUS}$ 에서 제공하는 사용자 정의 재료 서브루틴(UMAT)에 재료모델을 탑재하였다. 개발 UMAT의 검증을 위해 7\% 니 켈강 재료 인장시험 시률레이션을 수행하였으며, 이를 통해 재료정수를 획득하였다. 또한, 피로하중에 따른 손상해석에 있어 계산 시간 단축을 위한 jump-in-cycles 과정과 임계 손상 값 조정 및 피로 예비 균열 시뮬레이션을 수행하였고 이들 과정을 개발 UMAT에 탑재하여 해석을 수행하였다. 개발 UMAT을 활용하여 $7 \%$ 니켈강의 상온 FCGR 테스트 시뮬레이션을 수행 하였으며, 균열길이 $(a)$ 와 주기 수(number of cycles)의 관계 및 1 cycle 당 균열성장량 $(d a / d N)$ 과 응력확대계수 진폭 $(\Delta K)$ 의 관계 등의 결과를 실험결과와 비교하여 검증하였다.

핵심용어 : 피로균열 진전속도, 손상역학, 유한요소해석, ABAQUS 사용자 정의 재료 서브루틴 